\title{
BUILDING THE INTERNET OF THINGS FOR AN INTERCONNECTED WORLD
}

AS THE WORLD BECOMES EVER MORE DIGITALLY CONNECTED, OUR SYSTEMS

MUST BE UPDATED TO COPE WITH THESE INCREASING FLOWS OF VIRTUAL INFORMATION. DR ZILONG LIU IS PART OF A UNIVERSITY OF SURREY TEAM THAT IS DEVELOPING NEW 5G AIR INTERFACE TECHNIQUES TO ADDRESS THIS CHALLENGE

\section{IMAGINE THIS}

A man has a heart attack at home. A sensor on his wrist picks up the abnormalities in his pulse and immediately alerts the closest hospital. A self-driving ambulance is dispatched from the nearest hospital, with two paramedics in the back preparing the defibrillator. All the other autonomous vehicles on the road are notified of the ambulance's intended route and pull into other lanes accordingly, so its journey is swift and unimpeded. As the ambulance pulls into the driveway, the sensor tells the paramedics that the man's heart has just stopped. As soon as they enter the house, they know to begin defibrillation. The man's heart is restarted in seconds. His life has been saved, and all due to the rapid response time granted by streamlined machine-to-machine communications.

\section{DATA PACKETS}

The emails you read, the photos you share online and the films and music you stream are all, in fact, collections of electronic data. To be able to transmit these data over a digital network, they are broken down into tiny pieces and placed in digital or data packages. And, once they reach their destination, the information contained in the packets are reassembled. This is why you might see various parts of a photo coming together as it loads if the internet connection is slow.
We are now entering a new age where it is not only people that talk to each other over wireless networks: the devices we use do, too. This "Internet of Things" has vast potential, linking up everything from healthcare systems to traffic control. The amount of data and the number of communication links travelling wirelessly through the air are increasing dramatically, but we cannot keep churning out data; we need clever ways to transport them from one device to another so that the different data streams do not interfere with each other.

This is the issue that a team of scientists at the University of Surrey's 5G Innovation Centre is set on solving, led by Professor Pei Xiao, the principal investigator of the research project.

Transmitting data wirelessly involves converting it into radio waves that can travel through the air - this stage is called the air interface. However, the air interface processes wireless signals over very crowded and expensive radio frequencies (called "spectrum bands"), and sending too much data at once over these limited spectrum bands can lead to interference. "It is like sending lots of cars into a narrow street," says Dr Zilong Liu, a senior research fellow working on the $5 \mathrm{G}$ Innovation Centre's air interface project. "There could be very severe traffic jams if old-fashioned approaches are applied."
HOW DOES OUR CURRENT WIRELESS SYSTEM WORK?

As with anything electronic, wireless communications are based on circuits. A change in one device (e.g. the transmission of data) causes a change in another device (e.g. the reception of data). But electrical currents do not travel well through the air; so, to reach devices, the data has to be transformed into something else, namely radio waves.

Up until now, our wireless system has largely avoided interference between different signals by using the orthogonal multiple access (OMA) principle. "Orthogonal" means "at right angles", and is used to describe data streams that are separated by allocating different radio resources to them - for instance, putting them on different frequencies - so that they cannot be confused with one another. This has worked so far, but as we enter the age of the Internet of Things, the sheer number of device-todevice communications - known as massive machine-type communications (mMTC) - will grow explosively. For example, according to Cisco (a worldwide leader in IT, networking, and cybersecurity solutions), there will be 14.6 billion device-to-device connections by 2022, which is twice the size of the global population. This means that the frequencies used are in danger of becoming clogged up. 


\section{ABOUT $m$ MTCs AND THE INTERNET OF THINGS}

\section{THE FIFTH GENERATION}

Each generation of wireless technology is defined by breakthroughs in air interfaces: by increasingly sophisticated encoding methods that mean data can be transmitted at ever greater speeds and volumes through the air. We are now on the cusp of the fifth generation, known as $5 \mathrm{G}$.

Our familiarity with 5G is largely via our mobile phones. Similar to the progression from $3 G$ to $4 G$, moving from $4 G$ to $5 G$ will vastly increase the amount of data we can transmit or receive, be this face-to-face video calls, streaming films or music videos, or downloading powerful apps. But behind the scenes is another major use for $5 \mathrm{G}$, which is perhaps more likely to revolutionise the way we live. This use is known as massive machinetype communications (mMTC), and is where the Internet of Things enters the picture.

\section{THE INTERNET OF THINGS}

The term "Internet of Things" refers to devices ("things") communicating without the need for human participation. "Machines already talk to each other without us doing anything - think about the apps on your mobile, or the satnav in a car. The Internet of Things is already a reality in our everyday lives," says Zilong. "For example, traditional wireless sensor networks (which have been used for forest fire detection and battlefield surveillance) may be regarded as an example of Internet of Things. But the size of the future Internet of Things may be far more massive."

\section{MASSIVE MACHINE-TYPE}

\section{COMMUNICATIONS}

mMTC will involve many thousands of devices communicating wirelessly with each other, without ever needing to involve a human. Such a vast network could streamline huge portions of our lives: our entire systems for transport, healthcare, security and many other sectors could all be interlinked to make collective automated decisions within milliseconds. Zilong gives some examples. "For instance, smart meters for utilities at home can upload meter readings to the cloud automatically without any human intervention; smart sensors in future factories could be capable of monitoring the entire environment of a factory (e.g., pressure, humidity, temperature, or sound) to enable highly productive manufacturing."
SO, IS THIS A GOOD TIME TO GET INTO ELECTRICAL AND ELECTRONIC ENGINEERING?

Modern life is hugely reliant on electricity and, as we enter the age of smart

technologies, this reliance is set to increase. Electrical and electronic engineers are, and will continue to be, in high demand. Working at the forefront of practical technology, experts in this field are responsible for improving the devices and systems we use every day - from mobile phones to renewable energy.

WHAT IS THE DIFFERENCE

BETWEEN ELECTRICAL AND

ELECTRONIC ENGINEERING?

To put it simply, electrical engineers deal with the supply and demand of power; whereas electronic engineers create, design and test electronic devices. Many university courses bundle the electrical and electronic engineering together. If you love technology and are excited about future technological advances - and their potential benefits to society - then following Li in his footsteps could be the path for you!

\section{OPPORTUNITIES IN ELECTRICAL AND ELECTRONICS ENGINEERING}

- Electrical and electronics engineers have skills that are useful across a wide range of industries, including research and development, telecommunications, engineering services, manufacturing and government.

- According to Glassdoor, the average UK salary for an electronics engineer is $£ 35.5 \mathrm{k}$ a year.

- Generally, employers in the field look for a bachelor's degree at a minimum. According to The Guardian's league table, the current top five UK universities for electrical and electronics engineering are Nottingham, Southampton, Surrey, Imperial College London, Bath.

- There are many internship schemes taking place across the UK, requiring varying levels of qualifications to secure. Well-known companies offering internship positions include Arm, General Motors, BAE Systems and many more.

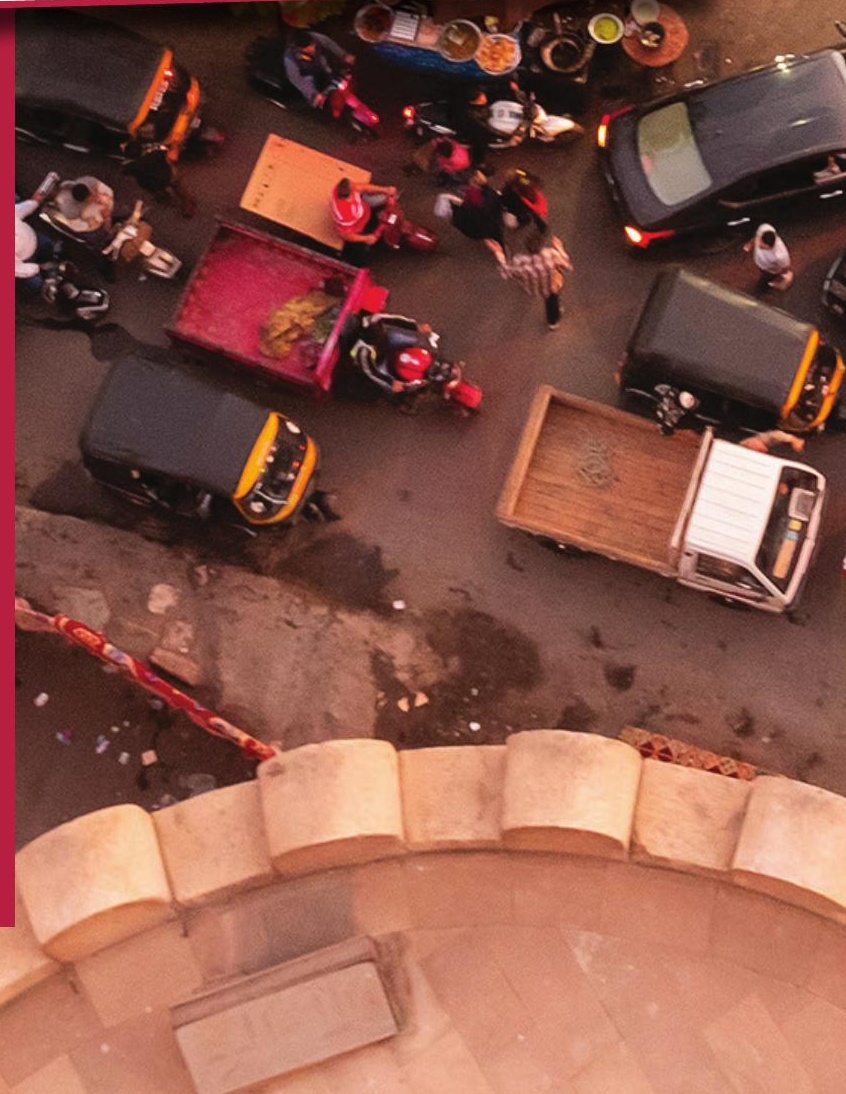




\section{ASK DR ZILONG LIU}

WHAT DID YOU WANT TO BE WHEN YOU WERE YOUNGER?

When I was young, we didn't have the internet and the world was not as connected as it is today. To be frank, I cannot recall what I wanted to be. I was very innocent but also curious about the entire world. As I came from a humble background, I studied very hard in order to get into a top university.

\section{WHAT INSPIRED YOU TO PURSUE} ELECTRICAL AND ELECTRONIC ENGINEERING?

A degree in electrical/electronic engineering can lead you to an engineering job with decent pay. Perhaps this is what motivated me to enter this field. After my undergraduate study, I was very fortunate to receive an MSc scholarship from Tsinghua University (one of China's top universities), where I trained to become a digital integrated circuit (IC) design engineer. But I wasn't very good at working in the IC design industry, which is fast-paced. In July 2008, I was offered an associate research position with Prof Guan Yong Liang at Nanyang Technological University in Singapore. It was through this position that I completed a part-time PhD with distinction. For me, my time spent in Singapore was very happy.

\section{HOW WOULD YOU DESCRIBE} YOURSELF?

I regard myself as somebody with enormous amounts of curiosity and passion, which are key personality traits for scientific discovery. Also, my team spirit and willingness to contribute brings me into contact with a lot of collaborators from Asia-Pacific and Europe.

WHAT EXCITES YOU MOST ABOUT THE FUTURE OF mMTC?

mMTC will pave the way for an increasingly intelligent future. I become very excited when, for instance, I imagine myself travelling to London from Guildford in an autonomous car operated with the aid of an mMTC network.

WHAT WOULD YOUR IDEAL "SMART HOME" LOOK LIKE?

I would like to have a smart home that could fulfil most of my everyday needs but with minimum human intervention. The smart home knows when I will arrive home, when to get my dinner ready, and when to wash all the dishes. It pays all the monthly bills and can even negotiate lower prices and better services from various service providers; for example, energy companies. The smart home automatically adjusts indoor temperatures and can open and close the windows, based on the season and daily weather reports.

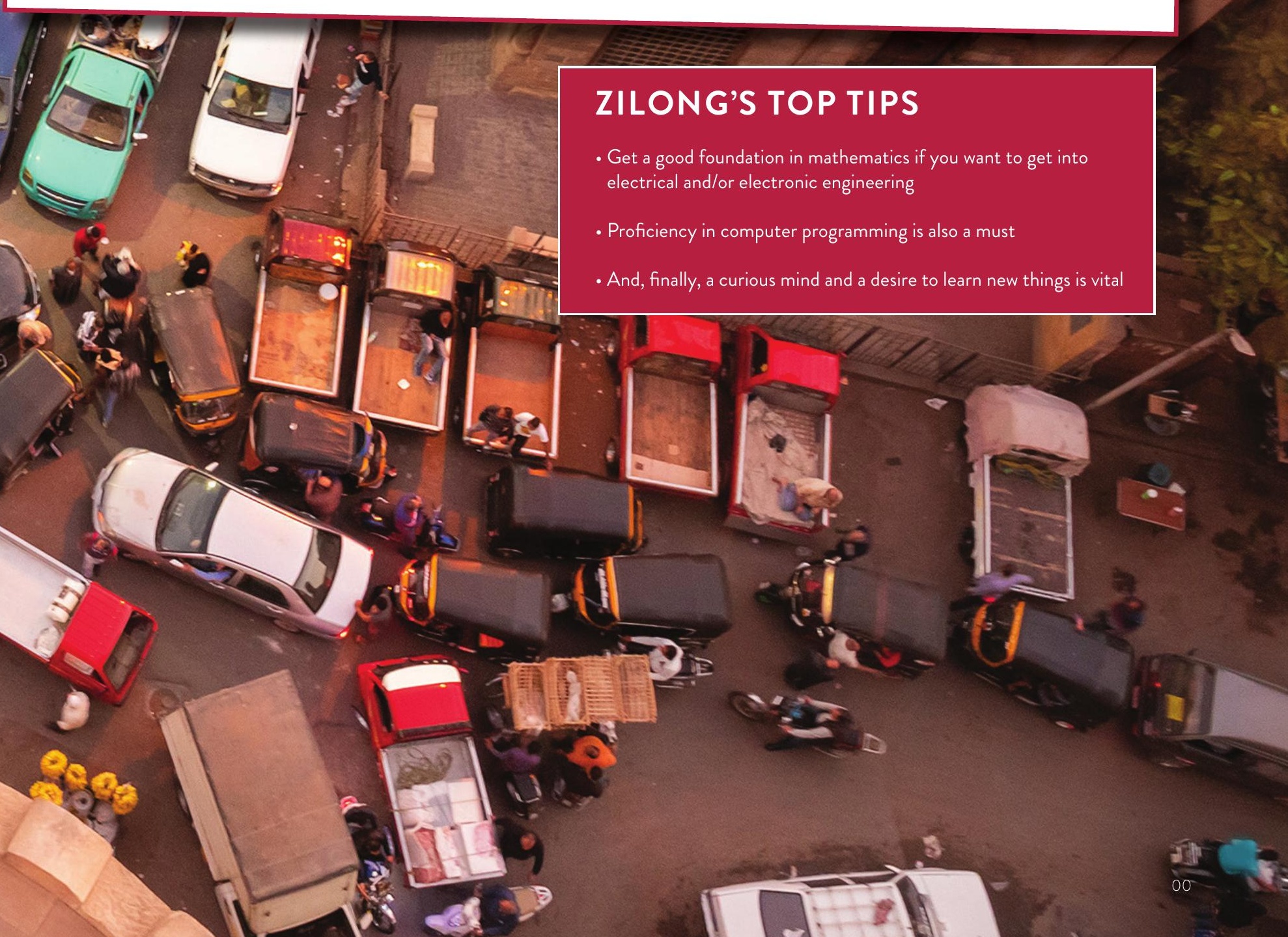

